\title{
Update on peripheral mechanisms of pain: beyond prostaglandins and cytokines
}

\author{
Hans-Georg Schaible*, Andrea Ebersberger and Gabriel Natura
}

\begin{abstract}
The peripheral nociceptor is an important target of pain therapy because many pathological conditions such as inflammation excite and sensitize peripheral nociceptors. Numerous ion channels and receptors for inflammatory mediators were identified in nociceptors that are involved in neuronal excitation and sensitization, and new targets, beyond prostaglandins and cytokines, emerged for pain therapy. This review addresses mechanisms of nociception and focuses on molecules that are currently favored as new targets in drug development or that are already targeted by new compounds at the stage of clinical trials - namely the transient receptor potential V1 receptor, nerve growth factor, and voltage-gated sodium channels - or both.
\end{abstract}

\section{Introduction}

Pain research substantially amplifies our understanding of the nature and mechanisms of pain, and this area is still expanding. We have learned that different forms of pain can be distinguished according to their pathogenesis (for example, nociceptive versus neuropathic pain) (see the following section), and we are beginning to decipher the molecular mechanisms involved in different types of pain. Importantly, this research provided new targets for pain treatment, and different classes of compounds that are effective against pain in animal models and that are now being tested in humans in different phases of clinical trials have emerged. The two main challenges are the efficacy(are the new drugs better than the old ones?) and the side effects (are they less dangerous than the old ones?). The need for better treatment of pain is evident because worldwide about $20 \%$ of adults suffer from chronic pain $[1,2]$. In these patients, the current pain therapy is either not applicable for different reasons (for example, side effects) or not sufficient [1]. In this review, the focus will be on molecular targets which are currently favored in drug development and for which respective compounds are at different stages of clinical trials.

\section{The nature of pain}

It is important to note that pain has different facets. In normal tissue, pain is elicited by high-energy stimuli

\footnotetext{
* Correspondence: Hans-Georg.Schaible@mti.uni-jena.de

Institute of Physiology I/Neurophysiology, Jena University Hospital - Friedrich Schiller University, Teichgraben 8, D-07740 Jena, Germany
}

that potentially or actually damage the tissue (noxious stimuli). This 'physiological nociceptive pain' is a warning sensation and absolutely essential for survival because it triggers adequate avoidance reactions. Pain treatment must not impair this type of pain. On the other hand, pain is an important symptom of disease, and this pain has to be treated because it impairs normal life [1]. The pain elicited by inflammation or injury of an organ is called 'pathophysiological nociceptive pain'. This pain is typically elicited by low-energy stimuli that are normally innocuous and not painful. It appears as allodynia (occurrence of pain upon an innocuous stimulus) or hyperalgesia (more pain during the application of noxious stimuli) or both, and resting pain (in the absence of any intentional stimulation) may also occur. Pathophysiological nociceptive pain results from the sensitization of the pain system (see the following section), and the interference with the mechanisms of sensitization provides the opportunity of treatment without eliminating the physiological nociceptive pain $[2,3]$. Initially, this pain is beneficial because it indicates the presence of disease and triggers measures for the support of healing (cancer is so dangerous because it does not cause pain in its early stage). However, chronic pain, in particular, creates severe suffering [1].

Whereas 'nociceptive pain' results from noxious stimulation or inflammation/injury of tissue, 'neuropathic pain' is evoked by damage to the neurons of the nociceptive system themselves. Causes include nerve damage, metabolic diseases (for example, diabetes mellitus), and herpes 
zoster. Neuropathic pain does not primarily signal noxious tissue stimulation, often feels abnormal (burning or electrical character), and can be persistent or occur in short episodes (for example, trigeminal neuralgia). It may be combined with hyperalgesia and allodynia or with sensory loss $[2,3]$. This pain requires treatment that is, however, often not sufficient. Its mechanisms differ in part from those of nociceptive pain.

\section{Neurophysiology of peripheral nociceptors in health and disease}

Noxious stimuli are detected by nociceptors that are present in almost all organs. These specialized sensory neurons have $\mathrm{A} \delta$ - and $\mathrm{C}$-fibers in the peripheral nerve and sensory non-corpuscular 'free nerve endings' in the innervated organs. Most nociceptors are polymodal, responding to noxious mechanical stimuli (painful pressure, squeezing the tissue), noxious thermal stimuli (heat or cold), and noxious chemical stimuli. They are equipped with sensor molecules in the sensory endings which transduce these mechanical, thermal, and chemical stimuli into a depolarizing sensor potential [2-5] (Figure 1). When this depolarization is sufficiently large, it opens voltage-gated $\mathrm{Na}^{+}$channels and triggers the generation of action potentials that are conducted to the dorsal horn of the spinal cord or the brainstem (Figure 1). From their sensory endings, the peptidergic nociceptors can release the neuropeptides substance $\mathrm{P}$ and calcitonin gene-related peptide (CGRP), which induce vasodilatation, plasma extravasation, and other effects, thus producing a 'neurogenic inflammation' [6].

Inflammation sensitizes polymodal nociceptors. Their excitation threshold drops such that even light, normally innocuous stimuli activate the fibers, and noxious stimuli evoke stronger responses than in the non-sensitized state. In addition, inflammation recruits so-called silent nociceptors for activation [2,3,7]. These C-fibers are inexcitable by noxious mechanical or thermal stimuli in normal tissue but inflammation sensitizes them to become responsive to stimuli. This 'peripheral sensitization' induces a hyper-excitability of nociceptive neurons in the central nervous system ('central sensitization'), and the two together generate the features of pathophysiological nociceptive pain, namely allodynia and hyperalgesia $[2,8,9]$. Peripheral sensitization is induced by inflammatory mediators that change the response properties of ion channels through the activation of second messenger systems (Figure 1).

The pathophysiology of neuropathic pain is different. While in healthy sensory nerve fibers action potentials are generated in the sensory endings upon stimulation of the receptive field, damaged nerve fi bers (including non-nociceptive $A \beta$-fibers [10]) often show pathological ectopic discharges that are generated at the site of nerve injury or in the cell body in dorsal root ganglia (DRGs) $[3,11]$. Neuropathic pain may also be generated by intact nerve fibers in the vicinity of injured nerve fibers [12]. Ectopic discharges are thought to be produced by changes in the expression of ion channels [13], pathological activation of axons by inflammatory mediators [14], and pathological activation of injured nerve fibers by the sympathetic nervous system [15].

However, the question of whether there is always a strict distinction between these types of pain under clinical conditions arises. For example, osteoarthritic pain is considered mainly a pathophysiological nociceptive pain because the joints may show severe damage and inflammation [16]. However, changes that are typical for neuropathic conditions may occur in the nervous system [17]. Possibly, pain types become less discernible with time.

Another emerging aspect of pain is that significant differences between the nociceptive innervation and processes in different tissues exist. First, the skin is innervated by two large populations of nociceptors, namely peptidergic (containing substance $P$ and CGRP) and non-peptidergic IB4 (isolectin B4)-positive nociceptive aerents $[2,5]$, whereas the vast majority of aerents in the musculoskeletal system are peptidergic $[18,19]$. Second, nociceptors in skin and musculoskeletal system have relatively high mechanical thresholds that clearly distinguish them from non-nociceptive low-threshold sensory fibers $[20,21]$, whereas most putative nociceptors in the viscera have their excitation threshold in the innocuous range [22]. Third, during inflammation, nociceptors in the muscle and joint are strongly sensitized to mechanical stimuli whereas cutaneous nociceptors are rather sensitized to thermal stimuli $[20,21,23]$. These differences, often ignored, may have a significant impact on drug development. Although there is an overlap of nociceptive mechanisms in different tissues, the awareness of tissue-specific nociceptive mechanisms may become more important in the future [2]. Notably, most chronic pain occurs during diseases of the musculoskeletal system whereas skin diseases are rarely painful [1].

\section{Principles of molecular mechanisms of nociception and sensitization}

The identification of these mechanisms is based on different experimental approaches. Electrophysiological and behavioral experiments in the intact organism are used to study nociceptive processes in situ. However, the sensory free nerve endings themselves cannot be accessed in situ for recordings, because they are extremely small and embedded in the tissue. Fortunately, the more accessible somata of the nociceptors in the DRGs also express the relevant molecules. Therefore, patch clamp recordings are usually carried out in cultured DRG 


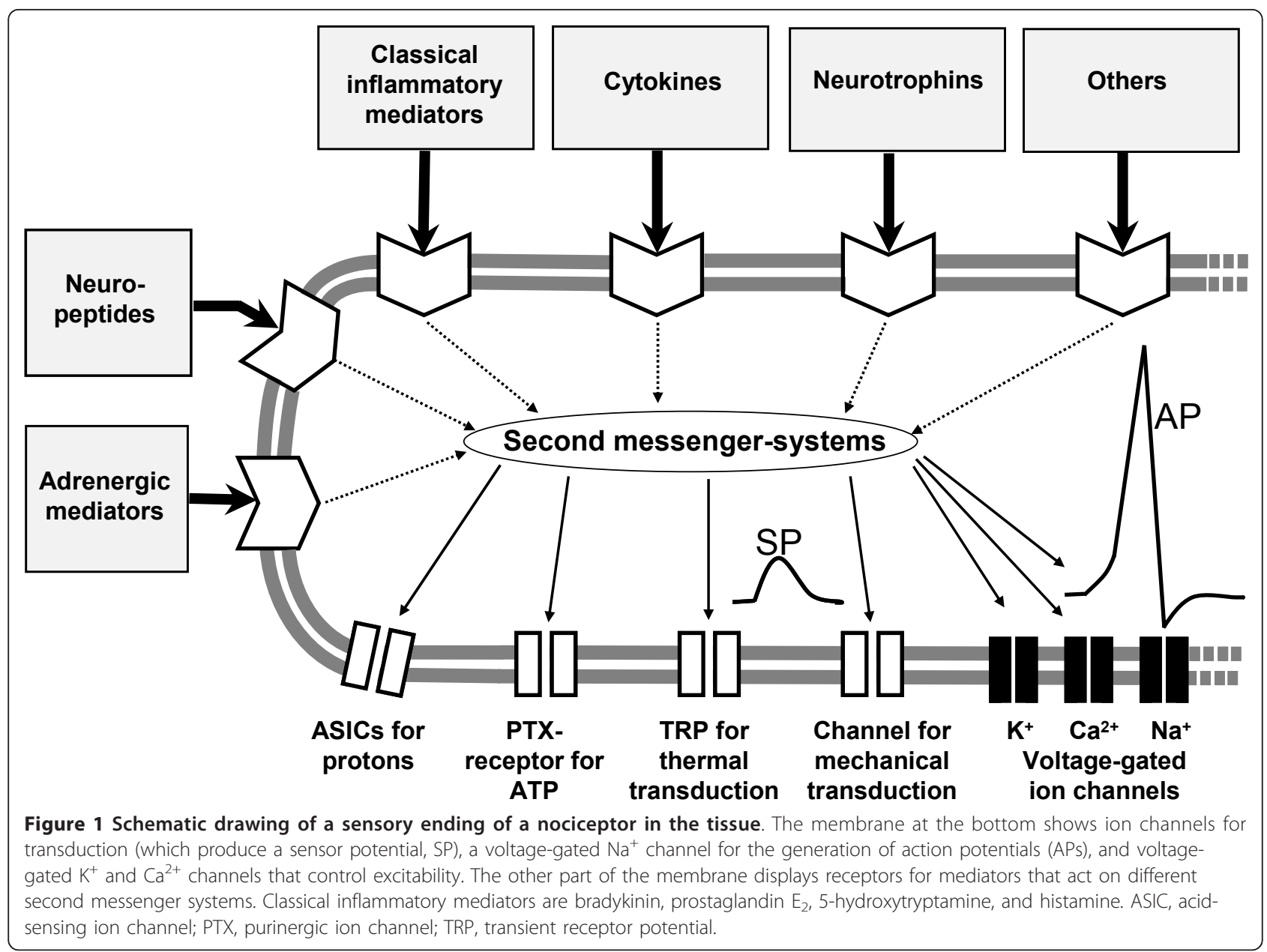

neurons, although subtle differences between the cell body and the endings in the tissue might exist [23]. Pain research aims to achieve convergent information from behavioral experiments in vivo (for example, in wildtype and knockout animals), invasive experiments in situ, and experiments in cultured neurons.

As mentioned, the excitation of nociceptor endings is produced by ion channels in the membrane which open upon the impact of physical stimuli to the membrane. The cation influx through these channels produces a local depolarization, the sensor potential. Once the ending is sufficiently depolarized by the influx of cations, voltagegated $\mathrm{Na}^{+}$channels are opened and action potentials are triggered (Figure 1). $\mathrm{K}^{+}$and $\mathrm{Ca}^{2+}$ channels control excitability of the neurons. During the process of sensitization, the gating properties of ion channels are modified by inflammatory mediators that act on metabotropic membrane receptors and activate second messenger systems [24]. Inflammatory mediators may also evoke neuropathic ectopic discharges [25]. Depending on the mediator, the sensitization of nociceptors can be induced within minutes (for example, by phosphorylation of ion channels in the membrane) or hours $[23,26,27]$. In the long term, the expression of receptors and ion channels may be regulated such that more molecules are available for stimulation [2]. These changes may be induced by inflammatory mediators such as cytokines $[28,29]$ and nerve growth factor (NGF) [30]. The following paragraphs address ion channels and receptors that were and are a major focus of pain research and some of them are the focus of drug development.

\section{The TRPV1 receptor}

A lot of effort is put into the development of antagonists against the transient receptor potential V1 (TRPV1) receptor, and it is hoped that these antagonists become new analgesics. In fact, clinical trials are under way. Why is there so much interest in the TRPV1 receptor? In the last 10 to 15 years, the TRPV1 receptor was one of the hot topics in pain research and is now considered one of the key molecules in nociception $[2,5]$. The TRPV1 receptor is a ligand-gated ion channel. Upon opening, cations (in particular, $\mathrm{Ca}^{2+}$ ) flow into the cell and depolarize it. Importantly, the TRPV1 receptor is expressed in nociceptors but not in other peripheral 
neurons [30]; that is, antagonists may selectively act on nociceptive neurons and not on other ones. Stimuli that open the TRPV1 receptor are manifold. First, it is opened by temperatures of higher than $43^{\circ} \mathrm{C}$, which are felt as painful heat by humans. TRPV1-deficient mice show attenuated responses to heat stimuli [5] but other molecules seem to contribute to noxious heat sensations as well [23]. Second, TRPV1 is opened by chemicals (such as capsaicin and ethanol applied to a wound) that elicit burning pain [30,31]. However, the main interest for analgesic therapy comes from the findings that the channel characteristics are modified by metabolites that occur in inflamed tissue. In fact, the TRPV1 is opened by low $\mathrm{pH}(<5.9)$ occurring in inflamed tissue and is activated by arachidonic acid metabolites produced by lipoxygenases such as 12-hydroperoxyeicosaenoic acid (12-HPETE) and by endocannabinoids such as anandamide and NADA (N-arachidonyl-dopamine) [30]. Further-more, TRPV1 is indirectly sensitized, via second messengers, by the inflammatory mediators bradykinin, prosta-glandin $\mathrm{E}_{2}$, extracellular ATP, glutamate, proteases, and NGF [25,27,30,31]. Cellularly, sensitization may be produced by the increase of TRPV1 expression level in the membrane, the phosphorylation by protein kinases, and the release of inhibition of TRPV1 by phosphatidyl-inositol-4,5-biphosphate [25]. The important consequence of this sensitization is that the threshold for opening by temperature stimuli drops such that normal body temperature may be sufficient to activate nociceptors and to elicit action potentials. This form of hyperalgesia is tested by thermal stimuli; in fact, TRPV1-deficient mice do not show the typical inflammation-evoked thermal hyperalgesia in acute carrageenan- or complete Freund's adjuvant (CFA)-induced inflammation [30,31].

However, there are some caveats that may limit the success of TRPV1 antagonists. First, in humans, inflammatory pain appears mainly as mechanical hyperalgesia (that is, the sensitization of the nociceptive system toward mechanical stimulation) $[2,3]$. The initial data showed that TRPV1-deficient mice exhibit normal responses to noxious mechanical stimuli and that inflammation-evoked mechanical hypersensitivity is not reduced [31]. Thus, TRPV1 was classified as a key molecule for thermal hyperalgesia but not for mechanical hyperalgesia [25]. Only recently, an involvement of TRPV1 in mechanical hyperalgesia was reported in adjuvant-induced chronic arthritis [32]. It is still unclear, therefore, whether TRPV1 receptor antagonists will be efficient against significant mechanical hyperalgesia (for example, during osteoarthritis). Second, the role of TRPV1 receptors in neuropathic pain is not well understood. While it was proposed that TRPV1 receptors are important in the generation of chemical and thermal hyperalgesia in neuropathy, even a protective role of TRPV1 against the development of mechanical hyperalgesia was observed [31]. Thus, the presence of a neuropathic pain component could spoil the success of TRPV1 receptor antagonists.

\section{Other TRPV receptors}

Sensory neurons also express other TRP receptors that can be colocalized with TRPV1. The functional significance of other TRPV receptors is much more uncertain or even confusing. Therefore, they are currently not considered targets for antinociceptive therapy, although they might be involved in aspects of nociception [25,31]. The TRPV2 receptor is activated by high temperature (threshold of about $52^{\circ} \mathrm{C}$ ) and may be the heat sensor in high-threshold-temperature A $\delta$ nociceptors. TRPV2 and TRPV1 are colocalized in a very small percentage of DRG neurons [31]. TRPV3 is activated by innocuous temperature stimuli in the range of $31^{\circ} \mathrm{C}$ to $39^{\circ} \mathrm{C}$ but shows increased responses to noxious thermal stimuli and may contribute to pain hypersensitivity during inflammation. It can be colocalized with the TRPV1 receptor [31]. TRPV4 is activated by innocuous warmth with a threshold of greater than $27^{\circ} \mathrm{C}$. Some data suggest that TRPV4 may, in fact, play a role in the transduction of mechanical stimuli and in mechanical hyperalgesia following exposure to inflammatory mediators [5]. The transient receptor potential A1 (TRPA1) was initially considered the transduction molecule for noxious cold stimuli because its activation threshold is below $18^{\circ} \mathrm{C}$ [31] (this skin temperature may feel painful), but there is no consensus whether TRPA1 is really a noxious cold sensor [5,33]. The transient receptor potential M8 (TRPM8) receptor is activated in the range of $23^{\circ} \mathrm{C}$ to $28^{\circ} \mathrm{C}$ and is also activated by cooling compounds such as menthol, eucalyptol, and icilin [31]. It is assumed that this particular TRP receptor might be the receptor for the sensation 'cool' (not painful) in non-nociceptive nerve fibers; in fact, TRPM8 is rarely colocalized with the other TRP receptors.

The involvement of other TRP receptors in nociception is suggested by their sensitivity to irritant mediators or mediators involved in inflammation or by the fact that they are upregulated under inflammatory conditions or by both. TRPV2 is upregulated in DRG neurons after intra-plantar injection of CFA [31]. TRPV3 shows responses to camphor and other irritants, nitric oxide (NO), and arachidonic acid and other fatty acids [31]. TRPV4 is activated by phorbolester, low $\mathrm{pH}$, citrate, endocannabinoids, arachidonic acid metabolites, and NO [31]. TRPA1 is activated by bradykinin and by pungent ingredients of mustard oil, garlic, and others, all of which induce an acute painful burning or pricking sensation [31]. 
It should be noted that TRP receptors are not confined to peripheral sensory neurons. They are also detected in the central nervous system and even in nonneuronal tissue. For example, TRPV4 is expressed in cochlear hair cells, and both TRPV3 and TRPV4 are expressed in keratinocytes [30,31]. Whether this restricts or prevents the usage of TRP antagonists as analgesic remains to be seen.

\section{Acid-sensing ion channels}

Acid-sensing ion channels (ASICs) are members of the $\mathrm{ENa} /$ degenerin family of highly selective $\mathrm{Na}^{+}$channels. They are expressed in numerous DRG neurons [5]. ASICs are activated by low extracellular $\mathrm{pH}$ and thus are important sensors of tissue acidosis, which often occurs during inflammation. Several isoforms of ASICs were reported [25]. Perhaps ASICs are most important in the skeletal muscle and heart, in which impaired circulation causes immediate pain [5,34].

\section{ATP and purinergic ion channels}

In some tissues, extracellular ATP is thought to act as a pain mediator. ATP opens purinergic receptors (P2X2 and P2X3) which are ligand-gated $\mathrm{Ca}^{2+}$ channels. ATP can be released from damaged cells or from keratinocytes of the inflamed skin [25]. Like protons, ATP may be particularly important in contracting muscles [34]. The $\mathrm{Ca}^{2+}$ influx depolarizes cells and causes secondary $\mathrm{Ca}^{2+}$ influx through voltage-gated $\mathrm{Ca}^{2+}$ channels. P2X activation was implicated in the development of inflammatory hyperalgesia [25].

\section{Voltage-gated $\mathrm{Na}^{+}$channels and other voltage- gated ion channels}

Voltage-gated $\mathrm{Na}^{+}$channels are essential for the generation and conductance of action potentials. The analgesic effect of local anesthetics is due to their ability to block voltage-gated $\mathrm{Na}^{+}$channels and thus to prevent the conduction of action potentials. Because local anesthetics block $\mathrm{Na}^{+}$channels in all nerve fibers (including motoneurons, touch receptors, and thermoreceptors), their long-term use for pain treatment is not feasible. However, recent research revealed that different types of $\mathrm{Na}^{+}$ channels exist and that some of them are particularly expressed in nociceptive neurons. Therefore, a lot of effort is put into research on $\mathrm{Na}^{+}$channels and their putative utilization for pain treatment.

Nociceptive neurons express mainly $\mathrm{Na}_{\mathrm{v}} 1.7, \mathrm{Na}_{\mathrm{v}} 1.8$, and $\mathrm{Na}_{\mathrm{v}} 1.9$, whereas large-sized non-nociceptive DRG neurons express mainly $\mathrm{Na}_{\mathrm{v}} 1.1, \mathrm{Na}_{\mathrm{v}} 1.6$, and $\mathrm{Na}_{\mathrm{v}} 1.7$ and some $\mathrm{Na}_{\mathrm{v}} 1.8$ [2,35]. $\mathrm{Na}_{\mathrm{v}} 1.1, \mathrm{Na}_{\mathrm{v}} 1.6$, and $\mathrm{Na}_{\mathrm{v}} 1.7$ can be blocked by tetrodotoxin (TTX) and are called TTX-sensitive (TTX-S), whereas $\mathrm{Na}_{\mathrm{v}} 1.8$ and $\mathrm{Na}_{\mathrm{v}} 1.9$ are TTXresistant (TTX-R). $\mathrm{Na}^{+}$influx into the neuron through
TTX-S $\mathrm{Na}^{+}$channels activates and inactivates very quickly, and $\mathrm{Na}^{+}$influx through TTX- $\mathrm{R} \mathrm{Na}^{+}$channels activates and inactivates more slowly. Most likely, conduction of action potentials in the axons of primary afferents rests mainly on TTX-S $\mathrm{Na}^{+}$channels, whereas TTX- $\mathrm{R} \mathrm{Na}^{+}$currents are important in the action potential generation in the sensory endings and the cell bodies [36]. The channels are up- or downregulated by second messenger pathways involving protein kinase A, protein kinase $C$, sphingomyelinase, calmodulin, and p38 mitogen-activated protein kinase [13].

The resting potential of DRG neurons is about $-60 \mathrm{mV}$. $\mathrm{Na}_{\mathrm{v}} 1.7$ opens after small depolarizations (at -50 to -40 $\mathrm{mV}$ ), and this initial $\mathrm{Na}^{+}$influx brings the neuron closer to the membrane potential for elicitation of an action potential [35]. $\mathrm{Na}_{\mathrm{v}} 1.8$, which is expressed only in sensory neurons and largely restricted to nociceptive neurons, opens at -30 to $-20 \mathrm{mV}$ - that is, when the cell has been pre-depolarized (for example, by $\mathrm{Na}_{\mathrm{v}} 1.7$ ) - and provides about $80 \%$ of the inward current of the upstroke of the action potentials in DRG neurons. In particular, this $\mathrm{Na}^{+}$ channel is targeted primarily to terminals and the cell body, suggesting a role in action potential initiation at the sensory terminal of nociceptors [13]. It also mediates repetitive action potentials during persistent membrane depolarization (for example, in the presence of inflammatory mediators) [35]. While $\mathrm{Na}_{\mathrm{v}} 1.7$ and $\mathrm{Na}_{\mathrm{v}} 1.8$ are directly involved in the generation of the action potential, $\mathrm{Na}_{\mathrm{v}} 1.9$ influences the threshold for action potentials. The channel opens around $-60 \mathrm{mV}$ and conducts persistent $\mathrm{Na}^{+}$currents at subthreshold voltages for action potential firing and thus regulates the distance between membrane potential and threshold; it does not contribute to the upstroke of the action potential [35].

The critical importance of these $\mathrm{Na}^{+}$channels in nociception is obvious from numerous findings. A gain-offunction mutation and a loss-of-function mutation of $\mathrm{Na}_{\mathrm{v}} 1.7$ channel in humans directly demonstrated the involvement of $\mathrm{Na}_{\mathrm{v}} 1.7$ current in pain perception [37]. During inflammation, $\mathrm{Na}_{\mathrm{v}} 1.7$ channel mRNA and protein are increased, and in mice with $\mathrm{Na}_{\mathrm{v}} 1.7$ deletion, inflammatory hypersensitivity is either absent or dramatically attenuated [13]. $\mathrm{Na}_{\mathrm{v}} 1.8$ current is increased by proinflammatory mediators such as adenosine, endothelin, NGF, prostaglandin $E_{2}$, serotonin, and tumor necrosis factor-alpha (TNF- $\alpha$ ) [13]. Antisense knockdown of $\mathrm{Na}_{\mathrm{v}} 1.8$ attenuates the development and maintenance of inflammatory hyperalgesia and can also prevent and reverse hypersensitivity observed following traumatic nerve injury [13]. $\mathrm{Na}_{\mathrm{v}} 1.9$ is also potentiated by inflammatory mediators [25].

The excitability of neurons may also be controlled by $\mathrm{K}^{+}$channels (for example, of the potassium voltagegated channel subfamily KQT [KCNQ] family) and $\mathrm{Ca}^{2+}$ 
channels. Excitability is increased when voltage-gated $\mathrm{K}^{+}$ channels are inhibited (this evokes sustained depolarization of neurons) or when $\mathrm{Ca}^{2+}$ flows into the neuron through voltage-gated T-type channels [25].

\section{Mediators activating, sensitizing, and altering nociceptive neurons}

Figure 1 schematically shows receptors for classes of inflammatory mediators without addressing all mediators and receptor subtypes in detail (this is beyond the scope of this review). It should be noted that not all of the receptors are located in all neurons. Instead, only subpopulations of neurons respond to certain mediators, but the nociceptive system as a whole is responsive to all of the mediators indicated.

'Classical inflammatory mediators' such as bradykinin and prostaglandins $[5,27,38]$ activate or sensitize neurons (or both) within minutes. For example, prostaglandin $E_{2}$ acts on $G$ protein-coupled prostaglandin $E$ receptors that increase cAMP. This activates protein kinase A, which finally leads to a phosphorylation of TRPV1 receptors and voltage-gated $\mathrm{Na}^{+}$currents. The importance of this sensitizing mechanism is underscored by the ability of prostaglandin synthesis inhibitors to reduce sensitization. More recent research showed that cytokines can induce long-lasting effects on the excitability and also produce prolonged effects such as regulation of receptor expression $[28,29]$. In this context, it may be important that, in the acute phase of inflammation, macrophages invade the DRGs of the segments that innervate the inflamed organ; that is, macrophages may directly influence the cell bodies [39]. The blockade of TNF- $\alpha$ signaling was found to reduce inflammatory hyperalgesia, at least in part by a neuronal target $[28,39,40]$.

A highly favored target for new drugs is NGF, and recent clinical studies using an antibody against NGF entered phase III [41] (with a set back, however, because the US Food and Drug Administration put a halt to some studies). Why is NGF a hot target? First, NGF is an essential growth factor for the development of normal nociceptors. In the adult, a large proportion of nociceptors remain dependent on the trophic effect of NGF. These neurons express tyrosine receptor kinase A (TrkA) receptors (specific receptor for NGF), and NGF is required for their structural and functional integrity [42]. Neutralization of NGF may thus disturb the nociceptive function of these neurons. Second, several cell types produce substantial amounts of NGF at inflammatory sites, and NGF can directly affect neurons. NGF enhances currents through TRPV1 channels and reduces the threshold of thermal excitation [30]. In vivo, the application of NGF generates hyperalgesia, and pretreatment with antibodies to NGF or a fusion protein attached to a modified TrkA receptor attenuates inflammation-induced hypersensitivity. Third, long-term exposure to NGF increases the expression of TRPV1, bradykinin receptors, $\mathrm{P} 2 \mathrm{X}$ receptors, $\mathrm{Na}^{+}$channels, and the synthesis of putative nociceptive transmitters such as substance P and CGRP [30]. Fourth, NGF stimulates inflammatory cells to release inflammatory compounds [30]. Thus, NGF is a key molecule for nociceptor biology, and its neutralization proved to be highly analgesic in humans [41]. It remains to be seen whether NGF neutralization will become a therapeutical option or whether NGF neutralization may impair the function of nociceptors too much.

\section{Mediators with inhibitory actions}

The drugs addressed so far reduce excitation/sensitization by neutralizing pronociceptive mediators and by interfering with ion channels of nociception. The multitude of mediators and ion channels involved in the generation of pain may limit the success of all efforts to treat pain by interfering with single molecules. Whether neutralization of NGF as a mediator with 'integrative functions' is feasible will be shown. Another principle of pain treatment is to employ drugs that stimulate endogenous inhibitory mechanisms. In fact, sensory neurons exhibit receptors that mediate inhibition of neuronal activity. Recently, peripheral opioid receptors were shown to produce profound antinociception experimentally as well as clinically [30]. Further receptors with inhibitory actions are receptors for somatostatin [43] and cannabinoids [44]. Experimentally, the use of specific agonists at these receptors produces antinociception [44-46]. However, the cannabinoid anandamid also activates TRPV1 receptors that may counteract antinociception [30,45].

\section{Conclusions}

Although peripheral mechanisms of nociception significantly contribute to the generation of pain, the contribution of spinal, as well as supraspinal, thalamocortical mechanisms to pain generation is essential $[47,48]$. As mentioned, peripheral sensitization often causes central sensitization $[8,9]$. This is even induced by a single intradermal injection of capsaicin, which activates TRPV1 receptors [49], and is quite prominent and longlasting during persistent inflammation in joints $[3,21]$. Thus, both peripheral and central nociceptive mechanisms are options for the improvement of pain therapy.

\section{Note}

This article is part of the series Evolving understanding of the biology of pain and its application to patient care, edited by Daniel Clauw and Anthony Jones. Other articles in this series can be found at http://arthritisresearch.com/series/pain 


\section{Abbreviations}

ASIC: acid-sensing ion channel; CFA: complete Freund's adjuvant; CGRP. calcitonin gene-related peptide; DRG: dorsal root ganglion; $\mathrm{Na}_{\mathrm{v}} \mathrm{x} . \mathrm{x}$ channel: voltage-gated sodium channel; NGF: nerve growth factor; NO: nitric oxide; P2X: purinergic receptor; TNF-a: tumor necrosis factor-alpha; TrkA: tyrosine receptor kinase A; TRP: transient receptor potential; TRPA1: transient receptor potential A1; TRPM8: transient receptor potential M8; TRPV1: transient receptor potential V1; TRPV2: transient receptor potential V2; TRPV3: transient receptor potential V3; TRPV4: transient receptor potential V4; TTX: tetrodotoxin; TTX-R: tetrodotoxin-resistant; TTX-S: tetrodotoxin-sensitive.

\section{Acknowledgements}

The authors thank the Deutsche Forschungsgemeinschaft for funding the position of author GN (Scha 404/13-1).

\section{Competing interests}

The authors declare that they have no competing interests.

Published: 28 April 2011

\section{References}

1. Breivik H, Beverly C, Ventafridda V, Cohen R, Gallacher D: Survey of chronic pain in Europe: prevalence, impact on daily life, and treatment. Eur Pain 2006, 10:287-333.

2. Gold MS, Gebhart GF: Nociceptor sensitization in pain pathogenesis. Nat Med 2010, 16:1248-1257.

3. Schaible H-G, Richter F: Pathophysiology of pain. Langenbecks Arch Surg 2004, 389:237-243

4. Belmonte C, Cervero E, (Eds): Neurobiology of Nociceptors Oxford: Oxford University Press; 1996.

5. Basbaum Al, Bautista DM, Scherrer G, Julius D: Cellular and molecular mechanisms of pain. Cell 2009, 139:267-284

6. Schaible H-G, Del Rosso A, Matucci-Cerinic M: Neurogenic aspects of inflammation. Rheum Dis Clin North Am 2005, 31:77-101.

7. Schmidt R, Schmelz M, Forster C, Ringkamp M, Torebjork E, Handwerker $H$ Novel classes of responsive and unresponsive $C$ nociceptors in human skin. J Neurosci 1995, 15:333-341.

8. Cervero F: Spinal cord hyperexcitablity and its role in pain and hyperalgesia. Exp Brain Res 2009, 196:129-137.

9. Sandkuhler J: Models and mechanisms of hyperalgesia and allodynia. Physiol Rev 2009, 89:707-758.

10. Devor M: Ectopic discharge in $A \beta$ afferents as a source of neuropathic pain. Exp Brain Res 2009, 196:115-128.

11. Janig W, Grossmann L, Gorodetskaya N: Mechano- and thermosensitivity of regenerating cutaneous afferent nerve fi bers. Exp Brain Res 2009 196:101-114.

12. Wu G, Ringkamp M, Hartke TV, Murinson BB, Campbell JN, Griffin JW, Meyer RA: Early onset of spontaneous activity in uninjured C-fiber nociceptors after injury to neighbouring nerve fi bers. J Neurosci 2001, 21:RC140, 1-5.

13. Gold MS: $\mathrm{Na}^{+}$channel blockers for the treatment of pain; context is everything, almost. Exp Neurol 2008, 210:1-6.

14. Sommer C, Kress M: Recent findings on how proinflammatory cytokines cause pain: peripheral mechanisms in infl ammatory and neuropathic hyperalgesia. Neurosci Lett 2004, 361:184-187.

15. Janig W, Levine JD, Michaelis M: Interactions of sympathetic and primary afferent neurons following nerve injury and tissue trauma. In The Polymodal Receptor: A Gateway to Pathological Pain. Progress in Brain Research. Volume 113. Edited by: Kumazawa T, Kruger L, Mizumura K Amsterdam: Elsevier Science; 1996:161-184

16. Bondeson J, Blom AB, Wainwright S: The role of synovial macrophages and macrophage-produced mediators in driving inflammatory and destructive responses in osteoarthritis. Arthritis Rheum 2010, 62:647-657.

17. Im H-J, Kim J-S, Li X, Kotwal N, Sumner DR, van Wijnen AJ, Davis FJ, Yan D, Levine B, Henry JL, Desevre J, Krin JS: Alteration of sensory neurons and spinal response to an experimental osteoarthritis pain model. Arthritis Rheum 2010, 62:2995-3005.

18. Nakajima T, Ohtori S, Inoue G, Koshi T, Yamamoto J, Takahashi K, Harada Y: The characteristics of dorsal-root-ganglia and sensory innervation of the hip in rats. J Bone Joint Surg Br 2008, 90:254-257.

19. Jimenez-Andrade JM, Mantyh WG, Bloom AP, Xu H, Ferng AS, Dussor G Vanderah TW, Mantyh PW: A phenotypically restricted set of primary afferent nerve fibres innervate the bone versus skin: therapeutic opportunity for treating skeletal pain. Bone 2010, 46:306-313.

20. McDougall J: Arthritis and pain: neurogenic origin of joint pain. Arthritis Res Ther 2006, 8:220-229.

21. Schaible H-G, Richter F, Ebersberger A, Boettger MK, Vanegas H, Natura G, Vazquez E, Segond von Banchet G: Joint pain. Exp Brain Res 2009, 196:153-162

22. Bielefeldt K, Gebhart GF: Visceral pain: basic mechanisms. In Wall and Melzack's Textbook of Pain. Edited by: McMahon SB, Koltzenburg M. Edinburgh: Elsevier Churchill Livingstone; 2006:721-736.

23. St Pierre M, Reeh PW, Zimmermann K: Differential role of TRPV channel block on polymodal activation of rat cutaneous nociceptors in vitro. Exp Brain Res 2009, 196:31-44.

24. Hucho T, Levine JD: Signaling pathways in sensitization: toward a nociceptor cell biology. Neuron 2007, 55:365-376.

25. Linley JE, Rose K, Ooi L, Gamper N: Understanding inflammatory pain: ion channels contributing to acute and chronic nociception. Pflügers Arch 2010, 459:657-669.

26. McCleskey EW, Gold MS: Ion channels of nociception. Annu Rev Physiol $1999,61: 835-856$

27. Mizumura K, Sugiura T, Katanosaka K, Banik RK, Kozaki Y: Excitation and sensitization of nociceptors by bradykinin: what do we know? Exp Brain Res 2009 , 196.53-65.

28. Schaible H-G, Segond von Banchet G, Boettger MK, Bräuer R, Gajda M, Richter F, Hensellek S, Brenn D, Natura G: The role of proinflammatory cytokines in the generation and maintenance of joint pain. Ann N Y Acad Sci 2010, 1193:60-69.

29. Üceyler N, Schäfers M, Sommer C: Mode of action of cytokines on nociceptive neurons. Exp Brain Res 2009, 196:67-78.

30. Stein C, Clark JD, Oh U, Vasko MR, Wilcox GL, Overland AC, Vanderah TW, Spencer RH: Peripheral mechanisms of pain and analgesia. Brain Res Rev 2009, 60:90-113.

31. Levine JD, Alessandri-Haber N: TRP channels: targets for the relief of pain. Biochim Biophys Acta 2007, 1772:989-1003.

32. Szabo A, Helyes Z, Sandor K, Bite A, Pinter E, Nemeth J, Banvolgyi A, Bolcskei K, Elekes K, Szolcsanyi J: Role of transient receptor potential vanilloid 1 receptors in adjuvant-induced chronic arthritis: in vivo study using genedeficient mice. J Pharmacol Exp Ther 2005, 314:111-119.

33. Belmonte C, Brock JA, Viana F: Converting cold into pain. Exp Brain Res 2009, 196:13-30

34. Mense S: Algesic agents exciting muscle nociceptors. Exp Brain Res 2009, 196:89-100.

35. Rush AM, Cummins TR, Waxman SG: Multiple sodium channels and their roles in electrogenesis within dorsal root ganglion neurons. J Physiol 2007, 579:1-14.

36. Pinto V, Derkach VA, Safronov BV: Role of TTX-sensitive and TTX-resistant sodium channels in $A \delta$ and $C$-fiber conduction and synaptic transmission. J Neurophysiol 2008, 99:617-628

37. Wada A, Wanke E, Gullo F, Schiavon E: Voltage-dependent $\mathrm{Na}_{v} 1.7$ sodium channels: multiple roles in adrenal chromaffin cells and peripheral nervous system. Acta Physiol (Oxf) 2008, 192:221-231.

38. McMahon SB, Bennet DLH, Bevan S: Inflammatory mediators and modulators. In Wall and Melzack's Textbook of Pain. Edited by: McMahon SB, Koltzenburg M. Edinburgh: Elsevier Churchill Livingstone; 2006:49-72.

39. Segond von Banchet G, Boettger MK, Fischer N, Bräuer R, Schaible H-G: Experimental arthritis causes tumor necrosis factor-a dependent infiltration of macrophages in rat dorsal root ganglia which correlates with pain-related behavior. Pain 2009, 145:151-159.

40. Inglis JJ, Notley CA, Essex D, Wilson AW, Feldmann M, Anand P, Williams R: Collagen-induced arthritis as a model of hyperalgesia: functional and cellular analysis of the analgesic actions of tumor necrosis factor blockade. Arthritis Rheum 2007, 56:4015-4023.

41. Lane NE, Schnitzer TJ, Birbara CA, Mokhtarani M, Shelton DL, Smith MD, Brown MT: Tanezumab for the treatment of pain from osteoarthritis of the knee. N Engl J Med 2010, 363:1521-1531.

42. Bennett D: NGF, sensitization of nociceptors. In Encyclopedia of Pain. Volume 2. Edited by: Schmidt RF, Willis WD. Berlin: Springer; 2007:1338-1342.

43. Bär K-J, Schurigt U, Scholze A, Segond von Banchet G, Stopfel N, Bräuer R, Halbhuber K-J, Schaible H-G: The expression and localisation of somatostatin receptors in dorsal root ganglion neurons of normal and monoarthritic rats. Neuroscience 2004, 127:197-206. 
44. Agarwal N, Pacher P, Tegeder I, Amaya F, Constantin CE, Brenner GJ, Rubino T, Michalski CW, Marsicano G, Monory K, Mackie K, Marian C,

Batkai S, Parolaro D, Fischer MJ, Reeh P, Kunos G, Kress M, Lutz B, Woolf CJ, Kuner R: Cannabinoids mediate analgesia largely via peripheral type 1 cannabinoid receptors in nociceptors. Nat Neurosci 2007, 10:870-879.

45. Kress M, Kuner R: Mode of action of cannabinoids on nociceptive nerve endings. Exp Brain Res 2009, 196:79-88.

46. Helyes Z, Szabó A, Németh J, Jakab B, Pintér E, Bánvölgyi Á, Kereskai L, Kéri G, Szolcsányi J: Anti-inflammatory and analgesic effects of somatostatin released from capsaicin-sensitive sensory nerve terminals in a Freund's adjuvant-induced chronic arthritis model in the rat. Arthritis Rheum 2004, 50:1677-1685.

47. Treede RD, Kenshalo DR, Gracely RH, Jones A: The cortical representation of pain. Pain 1999, 79:105-111.

48. Vogt BA: Pain and emotion. Interactions in subregions of the cingulated cortex. Nat Rev Neurosci 2005, 6:533-544.

49. Willis WD: The role of TRPV1 receptors in pain evoked by noxious thermal and chemical stimuli. Exp Brain Res 2009, 196:5-11.

doi:10.1186/ar3305

Cite this article as: Schaible et al.: Update on peripheral mechanisms of pain: beyond prostaglandins and cytokines. Arthritis Research \& Therapy 2011 13:210.

\section{Submit your next manuscript to BioMed Central} and take full advantage of:

- Convenient online submission

- Thorough peer review

- No space constraints or color figure charges

- Immediate publication on acceptance

- Inclusion in PubMed, CAS, Scopus and Google Scholar

- Research which is freely available for redistribution

Submit your manuscript at www.biomedcentral.com/submit 